\title{
PERANCANGAN SISTEM PAKAR IDENTIFIKASI JENIS IKAN MAS KOKI MENGGUNAKAN METODE FORWARD CHAINING BERBASIS ANDROID
}

\author{
Andre Renaldy Sihombing \\ PT. Meindo Elang Indah \\ e-mail: andresihombing15@gmail.com
}

\begin{abstract}
Abstrak
Ikan mas koki disenangi oleh penggemar ikan mas hias dalam pendidikan maupun masyarakat umum. Ikan mas koki di Indonesia terdapat beberapa jenis ikan mas koki populer yang sering dipelihara orang. Sebagai orang awam terkadang masih bingung untuk membedakan jenis-jenis ikan mas koki yang dijumpainya. Nama jenis ikan mas koki di suatu daerah biasanya berbeda dengan nama didaerah lainnya meskipun dari jenis ikan mas koki yang sama. Ini menyulitkan sesama orang pencinta ikan mas koki atau para pembudidaya ikan yang berurusan dengan ikan mas koki sebagai bisnis dalam dunia ikan hias. Diperlukannya seorang pakar ikan mas koki yang berpengalaman dalam mengidentifikasi jenis ikan mas koki. Padahal jumlah pakar ikan mas koki sangat sedikit, sehingga sulit ditemui setiap saat. Solusi yang ditawarkan dengan merancang aplikasi sistem pakar yang dapat mengidentifikasi jenis ikan mas koki berbasis android yang dapat mengidentifikasi jenis ikan berdasarkan bentuk badan, ekor, mata, kepala dan warna mas koki tersebut. Pada penelitian ini menggunakan metode System Development Life Cycle (SDLC) sebagai metode perancangan aplikasi, serta metode identifikasi menggunakan forward chaining. Kesimpulan dari penelitian ini adalah aplikasi identifikasi jenis ikan mas koki membantu pencinta ikan mas koki dalam mencari jenis ikan mas koki dengan benar. Aplikasi yang dibuat menghasilkan akurasi $87.5 \%$ dengan ketidak akuratan sistem sebesar $12.5 \%$. Adapun saran dari penelitian ini adalah diharapkan aplikasi ini dapat dibuat dan digunakan dengan menggunakan image recognizer pada ikan mas koki agar aplikasi ini dapat lebih mudah digunakan para pencinta ikan mas koki dalam mengidentifikasi jenis ikan mas koki yang diinginkan ke depannya.
\end{abstract}

Kata Kunci: Sistem Pakar, Ikan Mas Koki, Forward Chaining, Aplikasi Android

\section{DESIGN OF EXPERT IDENTIFICATION SYSTEM USING FORWARD CHAINING METHOD ON ANDROID}

\begin{abstract}
Goldfish are loved by ornamental goldfish enthusiasts in education and the general public. Goldfish in Indonesia, there are several types of popular goldfish that people often keep. As a layman, sometimes he is still confused about the types of goldfish he meets. The name of the type of goldfish in one area is usually different from the name in another area, even though it is from the same type of goldfish. This makes it difficult for fellow goldfish lovers or fish farmers who deal with goldfish as a business in the world of ornamental fish. It takes a goldfish expert who is experienced in identifying types of goldfish. In fact, the number of goldfish experts is very small, making it difficult to find at any time. The solution offered is by designing an expert system application that can identify types of goldfish based on android which can identify types of fish based on body shape, tail, eyes, head and color of the goldfish. This study uses the System Development Life Cycle (SDLC) method as an application design method, and the identification method uses forward chaining. The conclusion of this research is the application of identification of types of goldfish helps goldfish lovers in finding the type of goldfish correctly. Applications made produce an accuracy of $87.5 \%$ with a system inaccuracy of $12.5 \%$. The suggestion from this research is that it is hoped
\end{abstract}


that this application can be made and used by using the image recognizer on goldfish so that this application can be more easily used by goldfish lovers in identifying the type of goldfish desired in the future.

Keywords: Expert System, Goldfish, Forward Chaining, Android Application

\section{Pendahuluan}

Ikan mas koki adalah ikan hias yang asalnya dari negara Cina. Mas koki disenangi oleh para penggemar ikan hias dalam pendidikan maupun masyarakat umum. Ikan mas koki menjadi pembahasan perkembangan para pembudidaya ikan mas koki di dalam dunia pendidikan yang memperlihatkan perkembangan yang begitu pesat. Di Indonesia terdapat beberapa jenis ikan mas koki populer yang sering dipelihara orang. Sebagai orang awam terkadang masih bingung untuk membedakan jenis-jenis ikan mas koki yang dijumpainya. Nama jenis ikan mas koki di suatu daerah biasanya berbeda dengan nama didaerah lainnya meskipun dari jenis ikan mas koki yang sama. Ini menyulitkan sesama orang pencinta ikan mas koki atau para pembudidaya ikan yang berurusan dengan ikan mas koki sebagai bisnis dalam dunia ikan hias [1].

Ada sebagian orang yang menyukai ikan mas koki, namun tidak mengetahui nama dari jenis ikan mas koki yang diinginkan. Seorang yang menyukai ikan mas koki pun mendatangi toko ikan hias. Di toko ikan hias orang yang menyukai ikan mas koki menanyakan apa nama jenis ikan berdasarkan ciri-ciri ikan mas koki dari si pencinta ikan mas koki inginkan kepada si penjual ikan hias di toko ikan hias, tetapi si penjual pun tidak mengetahui ikan yang dimaksud. Diperlukannya seorang pakar ikan mas koki yang berpengalaman dalam mengidentifikasi jenis ikan mas koki. Padahal jumlah pakar ikan mas koki sangat sedikit, sehingga sulit ditemui setiap saat. Sistem Pakar Mengidentifikasi Jenis Ikan Mas Koki Menggunakan Metode Forward Chaining ini dapat dijadikan informasi dan pedoman untuk mendeteksi nama jenis dari ikan mas koki yang belum banyak diketahui para pencinta ikan mas koki.

Menurut Putri [2] sistem pakar merupakan salah satu cabang kecerdasan buatan yang mempelajari bagaimana mengadopsi cara seorang pakar berpikir dan bernalar dalam menyelesaikan suatu permasalahan, dan membuat suatu keputusan maupun mengambil kesimpulan dari sejumlah fakta yang ada. Sampai saat ini sudah ada beberapa hasil perkembangan sistem pakar dalam berbagai bidang sesuai dengan kepakaran seseorang. Pada penelitian ini akan dirancang suatu aplikasi Perancangan Sistem Pakar Identifikasi Jenis Ikan Mas Koki Menggunakan Metode Forward Chaining Berbasis Android.

Solusi yang ditawarkan dengan merancang aplikasi sistem pakar yang dapat mengidentifikasi jenis ikan mas koki berbasis android yang dapat mengidentifikasi jenis ikan berdasarkan bentuk badan, ekor, mata, kepala dan warna mas koki tersebut

\section{Studi Literatur}

\section{Ikan Mas Koki}

Menurut Bachtiar dalam Noviyanti, Tarsim, dan Maharani [3], ikan mas koki merupakan salah satu ikan yang memiliki berbagai bentuk tubuh dan berbagai warna yang bervariasi yaitu merah, kuning, hijau, hitam serta keperak-perakan sehingga banyak orang yang meminati ikan mas koki.

Menurut Hartono dan Purbosari [4], ikan mas koki (Carrasius auratus) adalah satu dari banyaknya ikan hias yang begitu digemari masyarakat dan juga karena nilai ekonomis yang tinggi bagi masyarakat. Bentuk tubuh serta perpaduan banyak warna yang terbentuk pada ikan koki adalah keindahan yang membuat ikan ini banyak yang meminati.

Berdasarkan pengertian dari penjelasan di atas mengenai ikan mas koki (Carrasius auratus), maka dapat diambil kesimpulan bahwa ikan mas koki (Carrasius auratus) merupakan salah satu ikan hias yang 
banyak digemari masyarakat karena bentuk tubuh dan perpaduan warna yang menarik sehingga membuat ikan ini banyak yang meminati.

\section{Pengertian Sistem Pakar}

Menurut Putri [2], sistem pakar (Expert System) adalah salah satu hasil dari perkembangan ilmu komputer, dalam bidang kecerdasan buatan (Artificial Intelegence), berguna memberikan jalan keluar agar dapat memecahkan masalah tersebut. Sistem yang berusaha meniru pengetahuan dari seorang pakar ke komputer, agar komputer dapat memberikan jalan keluar dari suatu masalah layaknya para pakar.

Menurut Meyliana, Kusrini, dan Luthfi [5], secara umum sistem pakar (Expert System) adalah sistem yang berusaha mengadopsi pengetahuan manusia yang di masukkan ke dalam komputer, agar manusia dapat menyelesaikan masalah sama seperti seorang pakar dalam memecahkan masalah. Sistem pakar membuat seorang awam pun dapat menyelesaikan masalah yang cukup rumit yang sebenarnya hanya dapat diselesaikan dengan bantuan para ahli.

Berdasarkan pengertian dari penjelasan di atas mengenai sistem pakar (Expert System), maka dapat di ambil kesimpulan bahwa sistem pakar (Expert System) adalah satu cabang kecerdasan buatan (Artificial Intelegence) yang berguna memecahkan masalah seorang awam dengan mengadopsi pengetahuan pakar ke dalam komputer dan memberikan jalan keluar dari masalah tersebut.

\section{Metode Inferensi}

Menurut Surbakti dan Kardian [6], inferensi adalah suatu proses yang dapat menghasilkan informasi dari fakta yang diketahui atau diasumsikan. Inferensi adalah konklusi logis (Logical Conclusion) atau implikasi berdasarkan informasi yang tersedia. Dalam sistem pakar, proses inferensi dapat dilakukan dalam suatu modul yang disebut mesin inferensi (Inference Engine).

Menurut Arifin [7], inferensi adalah suatu proses untuk menghasilkan informasi dari fakta yang ada dan diketahui atau implikasi berdasarkan informasi yang tersedia. Dalam sistem pakar proses inferensi di lakukan dalam suatu modul yang di sebut Inference Engine (mesin inferensi). Ada dua metode inferensi yang penting dalam sistem pakar yaitu Forward Chaining dan Backward Chaining.

1. forward chaining (runut maju)

Menurut Wilson dalam Arifin [7], forward chaining (runut maju) yang berarti bahwa menggunakan himpunan aturan kondisi-aksi. Dalam metode ini, data digunakan sebagai aturan mana yang dijalankan, kemudian aturan tersebut dijalankan. Proses diulangi sampai di temukan suatu hasil.

2. Backward chaining (runut balik)

Backward chaining (runut balik) merupakan proses perunutan yang arahnya kebalikan dari runut maju. Proses penalaran runut balik di mulai dengan tujuan/goa/lalu merunut balik ke jalur yang akan mengarahkan ke goa/tersebut, mencari bukti-bukti bahwa bagian kondisi terpenuhi.

Kedua metode inferensi tersebut dipengaruhi oleh tiga macam penelusuran, yaitu Depth-First Search, Breadth-First Search dan Best-First Search.

1. Depth-First Search.

Melakukan penelusuran di mulai dari simpul akar (node) dan bergerak turun ke dalam secara berurutan.

2. Breadth-First Search.

Cara kerjanya adalah bergerak dari simpul akar, simpul yang ada pada setiap tingkat diuji sebelum pindah ke tingkat selanjutnya.

3. Best-First Search.

Metode ini akan bekerja berdasarkan kombinasi metode Depth-first search dan Breadth-first search. 


\section{Android}

Menurut Sakul [8], android menyediakan aplikasi yang banyak akan framework yang dapat mengizinkan penggunanya untuk membuat aplikasi-aplikasi yang inovatif dan permainan untuk perangkat bergerak dalam lingkungan bahasa java. Konsep utama dari aplikasi framework adalah sebagai berikut:

1. Aplikasi yang menyediakan berbagai cara untuk masuk

Aplikasi android di buat sebagai kombinasi campuran dari komponen-komponen yang berbeda yang terlibat secara individu. Contohnya, activity menyediakan suatu layar tunggal sebagai penghubung dengan pengguna, dan layanan platform dengan sendirinya bekerja di background.

Dari satu komponen dapat memulai komponen lain menggunakan intent. Yaitu dapat memulai komponen dari aplikasi yang berbeda, seperti activity di aplikasi peta untuk mengarahkan alamat. Model ini memberikan berbagai cara untuk masuk dari satu aplikasi dan mengizinkan aplikasi yang lain untuk bertindak sebagai pengguna "default"agar aplikasi lain yang terlibat dapat bekerja.

2. Aplikasi yang beradaptasi ke berbagai perangkat

Android menyediakan aplikasi framework yang dapat beradaptasi, yang dapat mengizinkan pengguna untuk menyediakan sumber yang unik untuk pengaturan perangkat yang berbeda. Contohnya, pengguna dapat membuat tampilan $X M L$ yang berbeda untuk ukuran layar yang berbeda dan sistem dapat memilih tampilan mana yang akan di pakai berdasarkan ukuran layar yang sekarang di gunakan.

Pengguna dapat mengatur fitur yang tersedia dari perangkat pada saat android studio sedang berjalan jika ada fitur aplikasi yang membutuhkan perangkat keras yang spesifik layaknya kamera. Jika dibutuhkan, pengguna dapat mendeklarasikan fitur dari aplikasi pengguna yang membutuhkan suatu aplikasi belanja seperti Google Play Store untuk tidak dapat memasang aplikasi pada perangkat yang tidak mendukung fitur tersebut.

\section{Metode Penelitian}

Berisi penjelasan metode atau cara untuk melakukan penelitian, sehingga pembaca diharapkan dapat melakukan penelitian ulang, atau penelitian modifikasi. Metode harus di dukung dengan referensi yang jelas jika berhubungan dengan tulisan/penelitian yang sudah ada. Spesifikasi alat/bahan yang digunakan harus jelas, agar pembaca dapat mencari alat yang sama.

\section{Identifikasi dan Analisis Kebutuhan Aplikasi}

Berdasarkan permasalahan yang ditemukan, maka penulis mengusulkan pemecahan masalah dengan pembuatan aplikasi sistem pakar berbasis android. Aplikasi yang akan dirancang oleh penulis, merupakan aplikasi yang digunakan untuk memberikan jawaban berupa nama jenis ikan kepada pencinta ikan mas koki yang belum mereka ketahui. Dan oleh karena itu aplikasi yang akan memberikan jawaban, dengan cara pengguna memilih semua ciri-ciri yang sudah dibuat dalam aplikasi dan pengguna akan mendapatkan jawaban dari aplikasi.

\section{Akusisi Pengetahuan}

Dalam sistem yang dirancang oleh penulis terdapat kriteria dan subkriteria yang merupakan jawaban berdasarkan pengetahuan yang di kutip dari buku dan penelitian oleh seorang pakar atau ahli di bidang ikan mas koki. Kriteria adalah bagaimana seorang pengguna dapat memilih bentuk badan, ekor, mata, kepala dan warna. Sub-kriteria adalah ciri-ciri yang diketahui oleh pengguna untuk dimasukkan ke dalam sistem, sehingga pengguna dapat mengetahui nama jenis ikan mas koki. 
A. Membedakan ikan

Menurut Iskandar dan Sitanggang [9], mengemukakan bahwa dalam membedakan ikan berdasarkan bentuk badan, ekor, mata, kepala dan warna. Warna ikan mas koki dalam satu ekor ikan bisa satu warna, dua atau kombinasi beberapa warna.

B. Jenis-jenis ikan mas koki di Indonesia

Ada beberapa jenis ikan mas koki di Indonesia menurut Ardhya [10], yaitu Oranda, Teleskop, Lion Head, Mutiara, Ryukin, Bubble Eye, Butterfly, dan Ranchu.

C. Warna ikan mas koki

Menurut Iskandar dan Sitanggang [9], warna ikan mas koki dalam satu ekor ikan bisa satu warna, dua atau kombinasi beberapa warna. Satu warna yaitu merah, hitam, kuning, putih, cokelat, biru. Dua warna yaitu merah-putih, merah kuning, hitam-putih, hitam-cokelat, hitam-merah, putih-kuning. Dan pancawarna yaitu kombinasi berbagai warna, bisa tiga atau lebih warna yang biasa disebut Colico.

\section{Representasi Pengetahuan}

Berdasarkan pengetahuan dari setiap jurnal dan buku yang penulis telah paparkan dalam akusisi pengetahuan di atas, maka penulis merangkumkan nama jenis ikan beserta ciri-ciri dari masing-masing jenis ikan mas koki dalam bentuk tabel di bawah ini.

Tabel 1 Nama Ikan

\begin{tabular}{|c|l|}
\hline Kode & \multicolumn{1}{|c|}{ Nama Ikan } \\
\hline Ik0011 & Oranda Merah \\
\hline Ik0012 & Oranda Merah-Putih \\
\hline Ik0013 & Oranda Merah-Hitam \\
\hline Ik0014 & Oranda Kuning \\
\hline Ik0015 & Oranda Biru \\
\hline Ik0016 & Oranda Hitam \\
\hline Ik0017 & Oranda Colico \\
\hline Ik0021 & Teleskop Hitam \\
\hline Ik0022 & Teleskop Colico \\
\hline Ik0023 & Teleskop Merah \\
\hline Ik0024 & Teleskop Merah-Putih \\
\hline IK0025 & Teleskop Merah-Hitam \\
\hline Ik0031 & Bubble eye Merah \\
\hline Ik0032 & Bubble eye Merah-Putih \\
\hline Ik0033 & Bubble eye Merah-Hitam \\
\hline Ik0041 & Lion head Merah \\
\hline Ik0042 & Lion head Merah-Putih \\
\hline Ik0043 & Lion head Colico \\
\hline Ik0044 & Lion head Hitam \\
\hline Ik0045 & Lion head Merah-Hitam \\
\hline Ik0051 & Mutiara Merah-Putih \\
\hline Ik0052 & Mutiara Colico \\
\hline Ik0061 & Ryukin Merah \\
\hline Ik0062 & Ryukin Merah-Putih \\
\hline Ik0063 & Ryukin Merah-Hitam \\
\hline Ik0064 & Ryukin Colico \\
\hline Ik0071 & Butterfly Merah-Putih \\
\hline Ik0072 & Butterfly Merah-Hitam \\
\hline Ik0073 & Butterfly Merah \\
\hline Ik0074 & Butterfly Hitam \\
\hline Ik0081 & Ranchu Hitam \\
\hline Ik0082 & Ranchu Merah \\
\hline Ik0083 & Ranchu Merah-Putih \\
\hline Ik0084 & Ranchu Colico \\
\hline & \\
\hline
\end{tabular}


Tabel 2 Kriteria

\begin{tabular}{|c|c|}
\hline Kode & Nama Kriteria \\
\hline Kk001 & Badan \\
\hline Kk002 & Ekor \\
\hline Kk003 & Mata \\
\hline Kk004 & Kepala \\
\hline Kk005 & Warna \\
\hline
\end{tabular}

Tabel 3 Subkriteria

\begin{tabular}{|c|c|}
\hline Kode & Nama Subkriteria \\
\hline Bd1 & Badan bulat bersirip \\
\hline $\mathrm{Bd} 2$ & Badan memanjang \\
\hline $\mathrm{Bd} 3$ & Badan bulat gempal tidak mempunyai sirip \\
\hline $\mathrm{Bd} 4$ & Badan mempunyai sisik bintik bulat menonjol \\
\hline Bd5 & Badan tinggi membentuk segitiga ke arah kepala dan sirip tegak ke atas \\
\hline Bd6 & Badan seperti bungkuk \\
\hline Ek1 & Ekor pendek Membuka lebar ke atas tegak \\
\hline Ek2 & Ekor panjang menjuntai \\
\hline Ek3 & Ekor Membentang lebar \\
\hline Ek4 & Ekor berbentuk $\mathrm{x}$ dua sirip seperti kupu-kupu \\
\hline Mt1 & Mata bulat Oval \\
\hline Mt2 & Mata menonjol keluar layaknya teleskop \\
\hline Mt3 & Mata gelombang atau balon lembek \\
\hline Kp1 & Kepala dihiasi jambul layaknya topi \\
\hline Kp2 & Kepala segitiga menyamping \\
\hline Kp3 & Kepala berjambul di daerah kepala meninggi dan menyebar ke muka kepala terlihat besar \\
\hline Kp4 & Kepala terlihat kecil dan seperti segitiga \\
\hline Kp5 & Kepala dihiasi jambul hingga pipinya \\
\hline Wr1 & Merah \\
\hline Wr2 & Hitam \\
\hline Wr3 & Kuning \\
\hline Wr4 & Putih \\
\hline Wr5 & Cokelat \\
\hline Wr6 & Biru \\
\hline Wr7 & Colico \\
\hline
\end{tabular}

Tabel 4 pembentukan rule if-else

\begin{tabular}{|c|c|}
\hline If & Then \\
\hline Bd1, Ek1, Ek2, Mt1, Kp1,Wr1 & Oranda Merah (Ik0011) \\
\hline Bd1, Ek1, Ek2, Mt1, Kp1,Wr1,Wr4 & Oranda Merah-Putih (Ik0012) \\
\hline Bd1, Ek1, Ek2, Mt1, Kp1,Wr1,Wr2 & Oranda Merah-Hitam (Ik0013) \\
\hline Bd1, Ek1, Ek2, Mt1, Kp1,Wr3 & Oranda Kuning (Ik0014) \\
\hline Bd1, Ek1, Ek2, Mt1, Kp1,Wr2 & Oranda Hitam(Ik0015) \\
\hline Bd1, Ek1, Ek2, Mt1, Kp1,Wr7 & Oranda Colico (Ik0016) \\
\hline Bd1, Ek1, Ek2, Mt1, Kp1,Wr6 & Oranda Biru (Ik0017) \\
\hline Bd1, Bd2, Ek1, Mt2, Kp2, Wr2 & Teleskop Hitam (Ik0021) \\
\hline Bd1, Bd2, Ek1, Mt2, Kp2, Wr7 & Teleskop Colico (Ik0022) \\
\hline $\mathrm{Bd} 1, \mathrm{Bd} 2, \mathrm{Ek} 1, \mathrm{Mt2}, \mathrm{Kp2}, \mathrm{Wr} 1$ & Teleskop Merah (Ik0023) \\
\hline Bd1, Bd2, Ek1, Mt2, Kp2, Wr1, Wr4 & Teleskop Merah-Putih (Ik0024) \\
\hline Bd1, Bd2, Ek1, Mt2, Kp2, Wr1, Wr2 & Teleskop Merah-Hitam (Ik0025) \\
\hline Bd3, Bd6, Ek1, Ek2, Mt3, Kp2, Wr1 & Bubble eye Merah (Ik0031) \\
\hline Bd3, Bd6, Ek1, Ek2, Mt3, Kp2, Wr1, Wr4 & Bubble eye Merah-Putih (Ik0032) \\
\hline Bd3, Bd6, Ek1, Ek2, Mt3, Kp2, Wr1, Wr2 & Bubble eye Merah-Hitam (Ik0033) \\
\hline Bd3, Ek1, Mt1, Kp3, Wr1 & Lion head Merah (Ik0041) \\
\hline Bd3, Ek1, Mt1，Kp3，Wr1,Wr4 & Lion head Merah-Putih (Ik0042) \\
\hline Bd3, Ek1, Mt1, Kp3, Wr7 & Lion head Colico (Ik0043) \\
\hline
\end{tabular}




\begin{tabular}{|c|c|}
\hline Bd3, Ek1, Mt1, Kp3, Wr2 & Lion head Hitam (Ik0044) \\
\hline Bd3, Ek1, Mt1, Kp3, Wr1, Wr2 & Lion head Merah-Hitam (Ik0045) \\
\hline Bd1, Bd4, Ek3, Mt1, Kp1, Kp2,Wr1, Wr4 & Mutiara Merah-Putih (Ik0051) \\
\hline Bd1, Bd4, Ek3, Mt1, Kp1, Kp2,Wr7 & Mutiara Colico (Ik0052) \\
\hline Bd5, Ek2, Mt1, Kp4,Wr1 & Ryukin Merah (Ik0061) \\
\hline Bd5, Ek2, Mt1, Kp4,Wr1,Wr4 & Ryukin Merah-Hitam(Ik0063) \\
\hline Bd5, Ek2, Mt1, Kp4,Wr1,Wr2 & Ryukin Colico (Ik0064) \\
\hline Bd5, Ek2, Mt1, Kp4,Wr7 & Butterfly Merah-Putih(Ik0071) \\
\hline Bd1, Ek4, Mt1, Mt2, Kp2,Wr1,Wr4 & Butterfly Merah-Hitam(Ik0072) \\
\hline Bd1, Ek4, Mt1, Mt2, Kp2,Wr1,Wr2 & Butterfly Merah(Ik0073) \\
\hline Bd1, Ek4, Mt1, Mt2, Kp2,Wr1 & Butterfly Hitam(Ik0074) \\
\hline Bd1, Ek4, Mt1, Mt2, Kp2,Wr2 & Ranchu Hitam(Ik0081) \\
\hline Bd3, Bd6, Ek1, Mt1, Kp5, Wr2 & Ranchu Merah(Ik0082) \\
\hline Bd3, Bd6, Ek1, Mt1, Kp5, Wr1 & Ranchu Merah-Putih(Ik0083) \\
\hline Bd3, Bd6, Ek1, Mt1, Kp5, Wr1,Wr4 & Ranchu Colico(Ik0084) \\
\hline Bd3, Bd6, Ek1, Mt1, Kp5, Wr7 & \\
\hline
\end{tabular}

\section{Penjelasan Alur Algoritma}

Algoritma yang digunakan adalah metode forward chaining yaitu melakukan pencarian menggunakan pohon keputusan, yang melakukan pencarian menggunakan kondisi-aksi yang telah ditentukan berdasarkan data dari Iskandar dan Sitanggang [9] sebagai aturan mana yang dijalankan. Melakukan identifikasi dengan Breadth-first search yaitu cara kerjanya adalah bergerak dari simpul yang ada pada setiap tingkat diuji sebelum pindah ke tingkat selanjutnya. Didahului dengan bentuk badan berada di posisi pertama jika data sudah ditemukan dengan mecari pada setiap data yang tersedia maka akan menguji pada simpul berikutnya ekor, mata, kepala dan barulah warna jika pada bd1 tidak sesuai data yang diingikan maka akan mencari pada bd2 dan begitu pun berikutnya. Kemudian aturan tersebut dijalankan sampai di temukan suatu hasil. Berikut ini adalah pohon keputusan yang penulis buat:

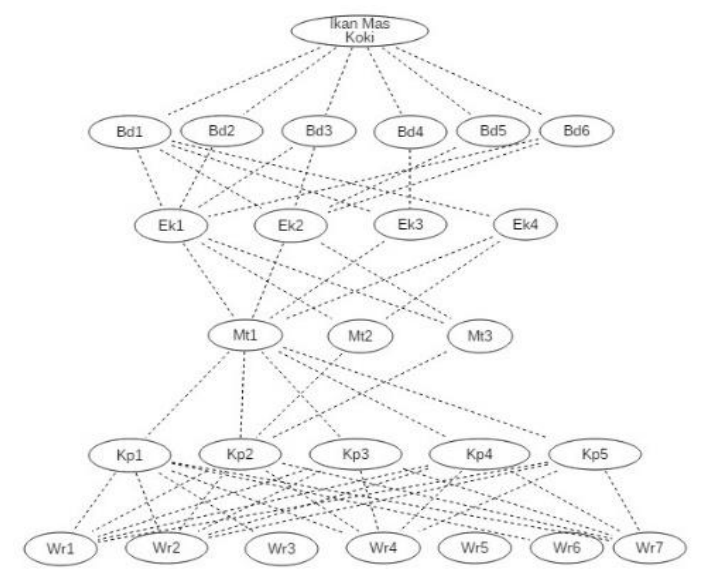

Gambar 1 Pohon Keputusan

\section{Hasil}

\section{Production Rules (Aturan Produksi)}

Production rules adalah suatu aturan yang dapat digunakan untuk melakukan penalaran atau penelusuran basis pengetahuan awal sehingga menghasilkan knowledge base yang berguna untuk 
mencapai tujuan. Aturan produksi pada dasarnya berupa ciri-ciri ikan mas koki yang ada. Antecedent yaitu bagian yang mempresentasikan situasi atau premis (pernyataan berawalan IF) dan konsekuen yaitu bagian yang menyatakan suatu tindakan tertentu atau konklusi yang diterapkan jika suatu situasi atau premis bernilai benar (pernyataan berawalan THEN). Pada aturan identifikasi ikan mas koki memiliki 8 aturan pada jenis ikan dan 34 warna yang berbeda dari ikan mas koki. Di bawah ini adalah aturan produksi yang digunakan aplikasi ini:

\section{Aturan 1.}

IF Bentuk badan bulat dan punggung bersirip AND

Bentuk ekor pendek membuka lebar ke atas tegak $O R$

Bentuk ekor panjang menjuntai

)

Bentuk mata bulat oval

AND

Bentuk kepala di hiasi jambul layaknya topi

$A N D$

THEN Ikan mas koki jenis Oranda

\section{Aturan 2.}

IF (

Bentuk badan bulat dan punggung bersirip $\quad O R$

)

Bentuk badan memanjang

AND

Bentuk ekor pendek membuka lebar ke atas tegak $\quad A N D$

Bentuk mata menonjol keluar layaknya teleskop AND

Bentuk kepala segitiga menyamping

THEN Ikan mas koki jenis Teleskop

\section{Aturan 3.}

IF (

Bentuk badan bulat gempal tidak mempunyai sirip $\quad O R$

)

Bentuk badan seperti bungkuk

$A N D$

Bentuk ekor pendek membuka lebar ke atas tegak $\quad O R$

)

Bentuk ekor panjang menjuntai

$A N D$

Bentuk mata gelombang atau balon lembek $\quad A N D$

Bentuk kepala segitiga menyamping

THEN Ikan mas koki jenis Bubble eye

\section{Aturan 4.}

IF Bentuk badan bulat gempal tidak mempunyai sirip $\quad A N D$

Bentuk ekor pendek membuka lebar ke atas tegak $\quad A N D$

Bentuk mata bulat oval AND

Bentuk kepala jambul dikepala meninggi dan menyebar

ke muka kepala terlihat besar

THEN Ikan mas koki jenis Lion head

\section{Aturan 5.}

IF (

Bentuk badan bulat dan punggung bersirip $O R$

)

Bentuk badan mempunyai sisik bintik bulat menonjol

Bentuk ekor membentang lebar

Bentuk mata bulat oval 
Bentuk kepala segitiga menyamping

Bentuk kepala dihiasi jambul layaknya topi

)

THEN Ikan mas koki jenis Mutiara

Aturan 6.

IF Bentuk badan punggung tinggi membentuk segitiga ke arah kepala dan sirip tegak ke atas

Bentuk ekor panjang menjuntai

Bentuk mata bulat oval

Bentuk kepala terlihat kecil dan seperti segitiga

THEN Ikan mas koki jenis Ryukin

\section{Aturan 7.}

IF Bentuk badan bulat dan punggung bersirip

Bentuk ekor berbentuk $x$ dua sirip seperti kupu-kupu

Bentuk mata teleskop

Bentuk mata bulat oval

)

Bentuk kepala segitiga menyamping

THEN Ikan mas koki jenis Butterfly

\section{Aturan 8.}

IF (

Bentuk badan bulat gempal tidak mempunya sirip

Bentuk badan seperti bungkuk

)

Bentuk ekor pendek membuka lebar ke atas tegak

Bentuk mata bulat oval

Bentuk kepala Jambul dikepala hingga pipi

THEN Ikan mas koki jenis Ranchu
AND

AND

$A N D$

$O R$

$O R$

$O R$

$A N D$

$A N D$

AND

$A N D$

$A N D$

$A N D$

Setelah menentukan jenis ikan mas koki barulah mengidentifikasi aturan produksi warna ikan mas koki. Seperti di bawah ini:

\section{Aturan Oranda.}

IF Ikan mas koki Oranda memiliki warna Merah

THEN Oranda Merah

IF Ikan mas koki Oranda memiliki warna Merah

AND

Ikan mas koki Oranda memiliki warna Putih

THEN Oranda Merah-Putih

IF Ikan mas koki Oranda memiliki warna Merah

Ikan mas koki Oranda memiliki warna Hitam

THEN Oranda Merah-Hitam

IF Ikan mas koki Oranda memiliki warna Kuning

THEN Oranda Kuning

IF Ikan mas koki Oranda memiliki warna Biru

THEN Oranda Biru

IF Ikan mas koki Oranda memiliki warna Hitam

THEN Oranda Hitam 
IF Ikan mas koki Oranda memiliki warna Colico THEN Oranda Colico

\section{Aturan Teleskop.}

IF Ikan mas koki Teleskop memiliki warna Hitam THEN Teleskop Hitam

IF Ikan mas koki Teleskop memiliki warna Colico THEN Teleskop Colico

IF Ikan mas koki Teleskop memiliki warna Merah THEN Teleskop Merah

IF Ikan mas koki Teleskop memiliki warna Merah

Ikan mas koki Teleskop memiliki warna Putih

\section{THEN Teleskop Merah-Putih}

IF Ikan mas koki Teleskop memiliki warna Merah

Ikan mas koki Teleskop memiliki warna Hitam

\section{THEN Teleskop Merah-Hitam}

\section{Aturan Lion Head.}

IF Ikan mas koki Lion Head memiliki warna Merah THEN Lion Head Merah

IF Ikan mas koki Lion Head memiliki warna Merah

Ikan mas koki Lion Head memiliki warna Putih

THEN Lion Head Merah-Putih

IF Ikan mas koki Lion Head memiliki warna Colico THEN Lion Head Colico

IF Ikan mas koki Lion Head memiliki warna Hitam THEN Lion Head Hitam

IF Ikan mas koki Lion Head memiliki warna Merah

Ikan mas koki Lion Head memiliki warna Hitam

\section{THEN Lion Head Merah-Hitam}

\section{Aturan Mutiara.}

IF Ikan mas koki Mutiara memiliki warna Merah

Ikan mas koki Mutiara memiliki warna Putih

\section{THEN Mutiara Merah-Putih}

IF Ikan mas koki Mutiara memiliki warna Colico

THEN Mutiara Colico

\section{Aturan Ryukin.}

IF Ikan mas Ryukin memiliki warna Merah

THEN Ryukin Merah

IF Ikan mas koki Ryukin memiliki warna Merah

Ikan mas koki Ryukin memiliki warna Putih

THEN Ryukin Merah-Putih

IF Ikan mas koki Ryukin memiliki warna Merah

Ikan mas koki Ryukin memiliki warna Hitam

THEN Ryukin Merah-Hitam

IF Ikan mas koki Ryukin memiliki warna Colico

THEN Ryukin Colico

\section{Aturan Bubble Eye.}

IF Ikan mas Bubble eye memiliki warna Merah

THEN Bubble eye Merah

IF Ikan mas koki Bubble eye memiliki warna Merah

Ikan mas koki Bubble eye memiliki warna Putih 
THEN Bubble eye Merah-Putih

IF Ikan mas koki Bubble eye memiliki warna Merah

$A N D$

Ikan mas koki Bubble eye memiliki warna Hitam

THEN Bubble eye Merah-Hitam

\section{Aturan Butterfly.}

IF Ikan mas koki Butterfly memiliki warna Merah

$A N D$

Ikan mas koki Butterfly memiliki warna Putih

THEN Butterfly Merah-Putih

IF Ikan mas koki Butterfly memiliki warna Merah

Ikan mas koki Butterfly memiliki warna Hitam

THEN Butterfly Merah-Hitam

IF Ikan mas Butterfly memiliki warna Merah

THEN Butterfly Merah

IF Ikan mas Butterfly memiliki warna Hitam

THEN Butterfly Hitam

\section{Aturan Ranchu.}

IF Ikan mas Ranchu memiliki warna Hitam

THEN Ranchu Hitam

IF Ikan mas Ranchu memiliki warna Merah

THEN Ranchu Merah

IF Ikan mas koki Ranchu memiliki warna Merah

$A N D$

Ikan mas koki Ranchu memiliki warna Putih

THEN Ranchu Merah-Putih

IF Ikan mas Ranchu memiliki warna Colico

THEN Ranchu Colico

\section{Halaman Identifikasi}

Tampilan halaman identifikasi seperti pada Gambar 2, halaman ini menampilkan lima tombol popup ciri-ciri di antaranya badan, ekor, mata, kepala, warna dan tersedia tombol proses, agar pengguna dapat memproses data yang pengguna input pada tombol popup.

\section{Halaman Popup Badan}

Tampilan halaman popup badan seperti pada Gambar 3, ketika tombol badan di-klik oleh pengguna maka popup akan tampil. Halaman ini untuk memilih ciri-ciri badan ikan mas koki yang pengguna ketahui.

\section{Halaman Popup Ekor}

Tampilan halaman popup ekor seperti pada Gambar 4, ketika tombol ekor di-klik oleh pengguna maka popup akan tampil. Halaman ini untuk memilih ciri-ciri ekor ikan mas koki yang pengguna ketahui. 


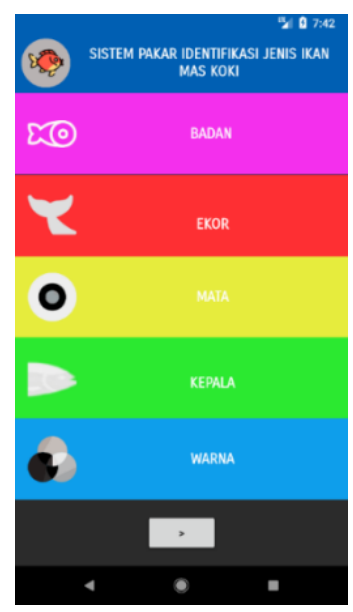

Gambar 2 Halaman Identifikasi

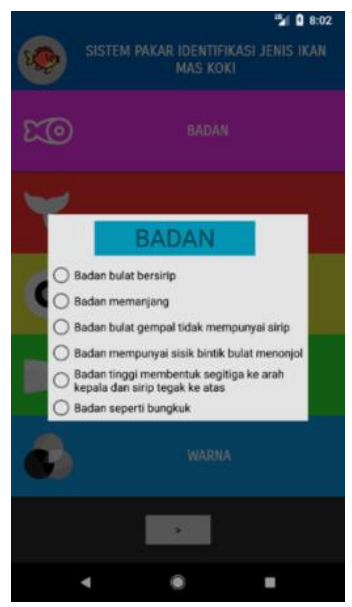

Gambar 3 Halaman Popup Badan

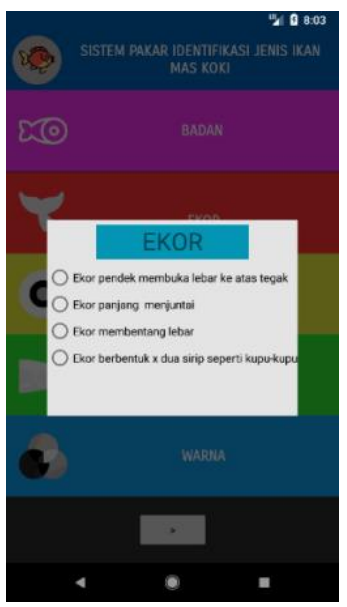

Gambar 4 Halaman Popup Ekor

\section{Halaman Popup Mata}

Tampilan halaman popup mata seperti pada Gambar 5, ketika tombol mata di-klik oleh pengguna maka popup akan tampil. Halaman ini untuk memilih ciri-ciri mata ikan mas koki yang pengguna ketahui.

\section{Halaman Popup Kepala}

Tampilan halaman popup kepala seperti pada Gambar 6, ketika tombol kepala di-klik oleh pengguna maka popup akan tampil. Halaman ini untuk memilih ciri-ciri kepala ikan mas koki yang pengguna ketahui.

\section{Halaman Popup Warna}

Tampilan halaman popup warna seperti pada Gambar 7, ketika tombol warna di-klik oleh pengguna maka popup akan tampil berbagai warna mulai dari hanya satu warna, kombinasi dua warna, dan kombinasi tiga warna yang disebut juga Colico. Halaman ini untuk memilih ciri-ciri warna ikan mas koki yang pengguna ketahui.

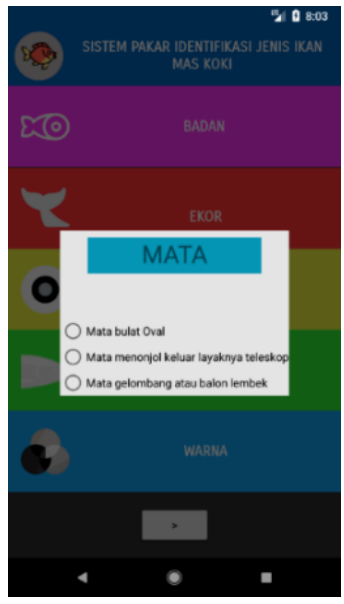

Gambar 5 Halaman Popup Mata

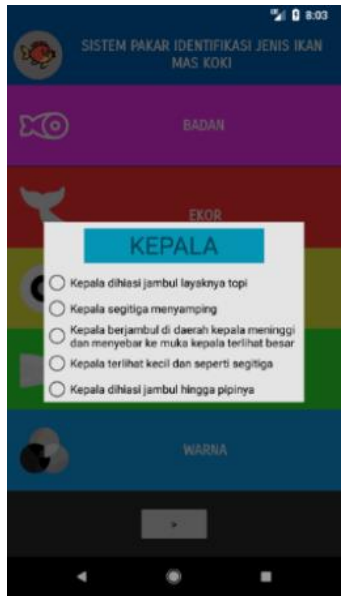

Gambar 6 Halaman Popup Kepala

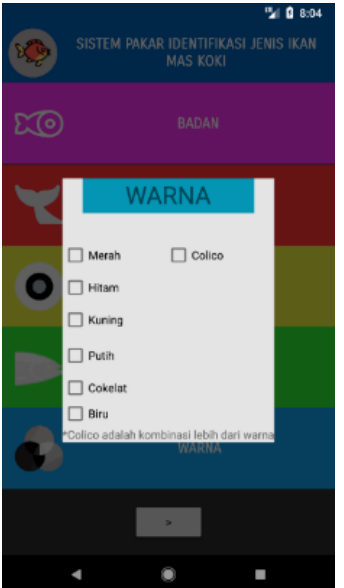

Gambar 7 Halaman Popup Warna 


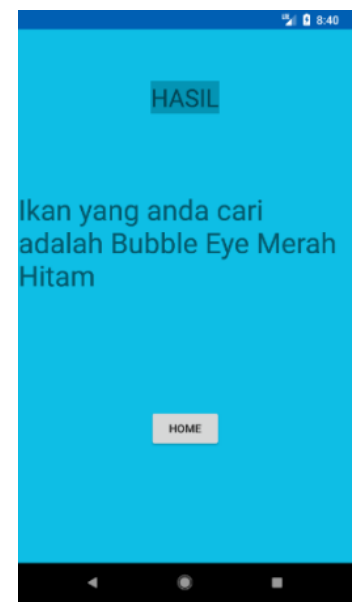

Gambar 8 Halaman Hasil (Benar)

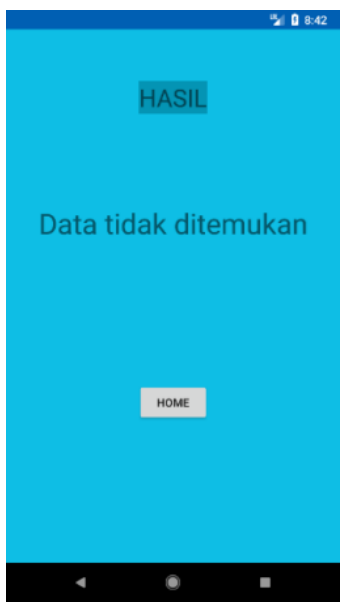

Gambar 9 Halaman Hasil (Salah)

\section{Halaman Hasil (Benar)}

Tampilan halaman hasil (benar) seperti pada Gambar 8, ketika memasukkan data yang sesuai oleh pengguna, lalu tombol proses di-klik oleh pengguna maka halaman proses akan tampil. Halaman ini untuk menampilkan hasil dari pengguna menginput semua ciri-ciri ikan mas koki yang pengguna ketahui. Tersedia tombol home agar pengguna dapat mengidentifikasi jenis ikan mas koki yang pengguna inginkan kembali.

\section{Halaman Hasil (Salah)}

Tampilan halaman hasil (salah) seperti pada Gambar 9, ketika memasukkan data yang tidak sesuai oleh pengguna, lalu tombol proses di-klik oleh pengguna maka halaman proses akan tampil. Halaman ini untuk menampilkan hasil dari pengguna menginput semua ciri-ciri ikan mas koki yang pengguna ketahui. Tersedia tombol home agar pengguna dapat mengidentifikasi jenis ikan mas koki yang pengguna inginkan kembali.

\section{Pengujian Identifikasi}

1. Notifikasi

Tabel 5 Pengujian Notifikasi

\begin{tabular}{|c|c|c|c|}
\hline Skenario pengujian & Test Case & Hasil yang Diharapkan & Kesimpulan \\
\hline Tombol badan & Meng-klik tombol ciri-ciri badan & $\begin{array}{l}\text { Tampil popup data ciri-ciri badan } \\
\text { yang tersimpan pada database }\end{array}$ & Diterima \\
\hline Tombol ekor & Meng-klik tombol ciri-ciri ekor & $\begin{array}{l}\text { Tampil popup data ciri-ciri ekor yang } \\
\text { tersimpan pada database }\end{array}$ & Diterima \\
\hline Tombol mata & Meng-klik tombol ciri-ciri mata & $\begin{array}{l}\text { Tampil popup data ciri-ciri mata } \\
\text { yang tersimpan pada database }\end{array}$ & Diterima \\
\hline Tombol kepala & Meng-klik tombol ciri-ciri kepala & $\begin{array}{l}\text { Tampil popup data ciri-ciri kepala } \\
\text { yang tersimpan pada database }\end{array}$ & Diterima \\
\hline Tombol warna & Meng-klik tombol ciri-ciri warna & $\begin{array}{l}\text { Tampil popup data ciri-ciri warna } \\
\text { yang tersimpan pada database }\end{array}$ & Diterima \\
\hline Semua popup & $\begin{array}{c}\text { User mengisi ciri-ciri dari tiap } \\
\text { popup agar menampilkan halaman } \\
\text { hasil }\end{array}$ & Menampilkan halaman hasil & Diterima \\
\hline Semua popup & $\begin{array}{l}\text { User hanya mengisi beberapa ciri- } \\
\text { ciri dari tiap popup maka akan } \\
\text { tampil pesan "Lengkapi data" }\end{array}$ & Tampil pesan "Lengkapi data" & Diterima \\
\hline Popup warna & $\begin{array}{l}\text { User mengisi lebih dari } 2 \text { warna } \\
\text { maka akan tampil pesan "Hanya } \\
\text { bisa memilih 2" }\end{array}$ & $\begin{array}{c}\text { Menampilkan pesan "Hanya bisa } \\
\text { memilih 2" }\end{array}$ & Diterima \\
\hline
\end{tabular}


2. Identifikasi

Tabel 6 Pengujian Identifikasi Data

\begin{tabular}{|c|c|c|c|}
\hline \multicolumn{4}{|c|}{ Kasus dan Hasil Uji (Data Benar) } \\
\hline Data Masukkan & Yang Diharapkan & Pengamatan & Kesimpulan \\
\hline Identifikasi & $\begin{array}{c}\text { Lima data yang dimasukkan benar } \\
\text { berdasarkan basis data lalu tekan } \\
\text { proses }\end{array}$ & $\begin{array}{l}\text { Menampilkan halaman hasil } \\
\text { benar }\end{array}$ & Diterima \\
\hline \multicolumn{4}{|c|}{ Kasus dan Hasil Uji (Data Salah) } \\
\hline Data Masukkan & Yang Diharapkan & Pengamatan & Kesimpulan \\
\hline Identifikasi & $\begin{array}{l}\text { Lima data yang dimasukkan tidak } \\
\text { sesuai berdasarkan basis data lalu } \\
\text { tekan proses }\end{array}$ & $\begin{array}{l}\text { Menampilkan halaman hasil } \\
\text { salah }\end{array}$ & Diterima \\
\hline
\end{tabular}

\section{Skenario Pengujian Beta}

Pengujian beta dilakukan agar dapat mengetahui sejauh mana kualitas dari perangkat lunak yang dibuat, apakah sudah sesuai dengan harapan atau belum. Maka dari itu dalam pengujian beta dilakukan penelitian dengan cara memberikan kuesioner pada calon pengguna perangkat lunak yang dibuat. Adapun metode penelitian yang digunakan adalah metode kuantitatif. Kuesioners diberikan kepada beberapa sample calon pengguna perangkat lunak yang dibangun. Berdasarkan data hasil kuesioner tersebut, dapat dicari persentase masing-masing jawaban dengan menggunakan rumus : $Y=P / Q * 100 \%$

Keterangan:

$$
\begin{aligned}
& P=\text { Banyaknya jawaban responden tiap soal. } \\
& Q=\text { Jumlah responden } \\
& Y=\text { Nilai Persentase }
\end{aligned}
$$

Berikut ini adalah hasil prosentase masing-masing jawaban yang sudah dihitung nilainya dengan menggunakan rumus di atas. Kuesioner ini diujikan kepada 10 orang kepada calon pengguna.

1. Apakah anda setuju bahwa aplikasi identifikasi jenis ikan mas koki ini dapat mempermudah cara menemukan jenis ikan mas koki?

Tabel 7 Hasil Pengujian Kuesioner Soal Nomor 1

\begin{tabular}{|c|c|c|c|}
\hline No. & Keterangan & Responden & Persentase (\%) \\
\hline A & Sangat Setuju & 1 & 10 \\
\hline B & Setuju & 6 & 60 \\
\hline C & Biasa Saja & 3 & 30 \\
\hline D & Kurang Setuju & 0 & 0 \\
\hline E & Tidak Setuju & 0 & 0 \\
\hline
\end{tabular}

Berdasarkan hasil persentase di atas maka dapat disimpulkan sebanyak 1 atau $10 \%$ menyatakan sangat setuju, 6 atau $60 \%$ menyatakan setuju, dan 3 atau 30\% menyatakan biasa saja bahwa aplikasi identifikasi jenis ikan mas koki ini dapat mempermudah cara menemukan jenis ikan mas koki

2. Apakah anda setuju bahwa tampilan android cukup menarik dan mudah dipahami serta user friendly?

Tabel 8 Hasil Pengujian Kuesioner Soal Nomor 2

\begin{tabular}{|c|c|c|c|}
\hline No. & Keterangan & Responden & Persentase (\%) \\
\hline A & Sangat Setuju & 3 & 30 \\
\hline B & Setuju & 4 & 40 \\
\hline C & Biasa Saja & 3 & 30 \\
\hline D & Kurang Setuju & 0 & 0 \\
\hline E & Tidak Setuju & 0 & 0 \\
\hline
\end{tabular}


Berdasarkan hasil persentase di atas maka dapat disimpulkan sebanyak 3 atau $30 \%$ menyatakan sangat setuju, 4 atau $40 \%$ menyatakan setuju, dan 3 atau 30\% menyatakan biasa saja bahwa tampilan android cukup menarik dan mudah dipahami user friendly.

3. Apakah anda setuju bahwa informasi mengenai identifikasi jenis ikan mas koki yang diberikan oleh android ini sesuai dengan informasi yang anda butuhkan?

Tabel 9 Hasil Pengujian Kuesioner Soal Nomor 3

\begin{tabular}{|c|c|c|c|}
\hline No. & Keterangan & Responden & Persentase (\%) \\
\hline A & Sangat Setuju & 1 & 10 \\
\hline B & Setuju & 7 & 70 \\
\hline C & Biasa Saja & 2 & 20 \\
\hline D & Kurang Setuju & 0 & 0 \\
\hline E & Tidak Setuju & 0 & 0 \\
\hline
\end{tabular}

Berdasarkan hasil persentase di atas maka dapat disimpulkan sebanyak 1 atau $10 \%$ menyatakan sangat setuju, 7 atau 70\% menyatakan setuju, dan 2 atau 20\% menyatakan biasa saja bahwa informasi mengenai identifikasi jenis ikan mas koki yang diberikan oleh android ini sesuai dengan informasi yang anda butuhkan.

\section{Kesimpulan Pengujian Beta}

Berdasarkan pengujian beta di atas, bahwa dapat diambil kesimpulan bahwa aplikasi identifikasi jenis ikan mas koki memudahkan user dalam mendapatkan informasi tentang jenis ikan mas koki. User dapat mengidentifikasi jenis ikan mas koki yang user ingin cari.

\section{Pengujian Akurasi}

Tabel 10 Hasil Pengujian Akurasi

\begin{tabular}{|c|c|c|c|c|}
\hline No. & $\begin{array}{l}\text { Ciri-ciri Pada Ikan } \\
\text { Mas Koki }\end{array}$ & $\begin{array}{l}\text { Hasil } \\
\text { Identifikasi } \\
\text { Sistem }\end{array}$ & $\begin{array}{l}\text { Hasil } \\
\text { Identifikasi } \\
\text { Pakar }\end{array}$ & $\begin{array}{l}\text { Akurasi Hasil } \\
\text { Perbandingan }\end{array}$ \\
\hline 1 & $\begin{array}{l}\text { Badan bulat bersirip, Badan mempunyai sisik bintik } \\
\text { bulat menonjol, Ekor Membentang lebar, Kepala } \\
\text { dihiasi jambul layaknya topi, Kepala segitiga } \\
\text { menyamping, Mata bulat Oval, Merah Putih }\end{array}$ & $\begin{array}{l}\text { Mutiara Merah } \\
\text { Putih }\end{array}$ & $\begin{array}{l}\text { Mutiara Merah } \\
\quad \text { Putih }\end{array}$ & 1 \\
\hline 2 & $\begin{array}{l}\text { Badan bulat bersirip, Ekor berbentuk x dua sirip } \\
\text { seperti kupu-kupu, Kepala segitiga menyamping, } \\
\text { Mata bulat Oval, Mata menonjol keluar layaknya } \\
\text { teleskop, Hitam. }\end{array}$ & Butterfly Hitam & Butterfly Hitam & 1 \\
\hline 3 & $\begin{array}{l}\text { Badan bulat gempal tidak mempunyai sirip, Ekor } \\
\text { pendek Membuka lebar ke atas tegak, Kepala } \\
\text { berjambul di daerah kepala meninggi dan menyebar } \\
\text { ke muka kepala terlihat besar, Colico }\end{array}$ & Lion Head Colico & Lion Head Colico & 1 \\
\hline 4 & $\begin{array}{l}\text { Badan bulat gempal tidak mempunyai sirip, Badan } \\
\text { seperti bungkuk, Ekor pendek membuka lebar ke } \\
\text { atas tegak, Ekor panjang menjuntai, Kepala segitiga } \\
\text { menyamping, Mata gelombang atau balon lembek, } \\
\text { Merah. }\end{array}$ & Bubble Eye Merah & Bubble Eye Merah & $\mathbf{0}$ \\
\hline 5 & $\begin{array}{l}\text { Badan bulat bersirip, Ekor pendek Membuka lebar ke } \\
\text { atas tegak,Ekor panjang menjuntai, Kepala dihiasi } \\
\text { jambul layaknya topi, Mata bulat Oval, Biru }\end{array}$ & Oranda Biru & Oranda Biru & 1 \\
\hline 6 & $\begin{array}{l}\text { Badan bulat gempal tidak mempunyai sirip,Badan } \\
\text { seperti bungkuk, Ekor pendek Membuka lebar ke } \\
\text { atas tegak, Kepala dihiasi jambul hingga pipinya, } \\
\text { Mata bulat Oval, Hitam }\end{array}$ & Ranchu Hitam & Ranchu Hitam & 1 \\
\hline 7 & $\begin{array}{l}\text { Badan tinggi membentuk segitiga ke arah kepala } \\
\text { dan sirip tegak ke atas, Ekor panjang menjuntai, } \\
\text { Kepala terlihat kecil dan seperti segitiga, Mata bulat } \\
\text { Oval, Merah }\end{array}$ & Ryukin Merah & Ryukin Merah & 1 \\
\hline 8 & $\begin{array}{l}\text { Badan bulat bersirip,Badan memanjang, Ekor } \\
\text { pendek Membuka lebar ke atas tegak, Kepala }\end{array}$ & Teleskop Merah & Teleskop Merah & 1 \\
\hline
\end{tabular}


Bedasarkan tabel diatas telah dilakukan dengan 8 sampel data identifikasi ikan mas koki dan menghasilkan nilai akurasi sesuai perhitungan berikut:

Nilai Akurasi $=\frac{\sum \text { match }}{\sum \text { tp }} \times 100 \%$

Jadi nilai ke akurasi $=\frac{7}{8} \times 100 \%=87.5 \%$

Jadi dapat disimpulkan bahwa akurasi sistem pakar berdasarkan 8 data yang diuji adalah $87.5 \%$ yang menunjukan bahwa sistem pakar ini berfungsi dengan baik sesuai dengan diagnosa pakar. Sistem pakar ini memiliki $12.5 \%$ data salah yang disebabkan karena beberapa kemungkinan antara lain kesalahan dalam penamaan ciri-ciri dalam identifikasi jenis ikan mas koki.

\section{Pembahasan/Kesimpulan}

Setelah menganalisis sistem dan permasalahan yang terjadi pada pencinta ikan mas koki, maka dapat disimpulkan bahwa:

1. Aplikasi identifikasi jenis ikan mas koki ini dapat diterapkan pada aplikasi android.

2. Dengan dibangunnya aplikasi identifikasi jenis ikan mas koki berdasarkan badan, ekor, mata, kepala, warna, pengguna dapat menemukan jenis ikan mas koki yang diinginkan.

3. Aplikasi yang telah dibangun dapat digunakan karena memiliki akurasi yang sesuai dengan data yang sudah dimasukkan pada firebase database.

4. Aplikasi sistem pakar yang telah dibangun memiliki tingkat keakurasian $87.5 \%$ yang menunjukkan aplikasi sistem pakar ini berjalan dengan baik.Berisi tentang perbandingan antara hasil yang diperoleh dengan sudah ada di literatur serta memberikan alasan jika ada perbedaan. Dapat berisikan kesimpulan dari penelitian maupun saran dan masukan untuk penelitian selanjutnya.

Adapun saran dari penelitian ini adalah diharapkan aplikasi ini dapat dibuat dan digunakan dengan menggunakan image recognizer pada ikan mas koki agar aplikasi ini dapat lebih mudah digunakan para pencinta ikan mas koki dalam mengidentifikasi jenis ikan mas koki yang diinginkan ke depannya.

\section{Referensi}

[1] Bowo A. T., Ginting G. (2015). SISTEM INTERAKTIF PEMELIHARAAN IKAN MAS KOKI MENERAPKAN METODE WEB BASED LEARNING. JURIKOM (Jurnal Riset Komputer) 2 (6)

[2] Putri, N. E. (2016). Sistem Pakar Kerusakan Hardware Komputer Dengan Metode Forward Chaining. Jurnal Momentum, 53.

[3] Noviyanti, K., Tarsim, \& Maharani, H. W. (2015). Pengaruh Penambahan Tepung Spirulina Pada Pakan Buatan Terhadap Intensitas Warna Ikan Mas Koki (Carassius auratus). e-Jurnal Rekayasa dan Teknologi Budidaya Perairan-Volume III No 2 Februari.

[4] Hartono, D. P., \& Purbosari, N. (2010). Perbaikan Mutu dan Peningkatan Produksi Ikan Mas Koki (Carrasius auratus) Melalui Rekayasa Set Kromosom. Jurnal Penelitian Pertanian Terapan Vol.10 (3): 144-149 ISSN 1410-5020.

[5] Meyliana, A., Kusrini, \& Luthfi, E. T. (2016). Sistem Pakar Pada Konsultasi Jenis Senam Dengan Metode Forward Chaining. Jurnal Informa Politeknik Indonusa Surakarta ISSN : 2442-7942 Vol. 1 Nomor 3. 
[6] Surbakti, J., \& Kardian, A. R. (2016). Sistem Pakar Kejiwaan denganForward Chaining Berbasis Web. Jurnal IImiah KOMPUTASI, Volume 15 Nomor : 1.

[7] Arifin, J. (2016). Sistem Pakar Diagnosa Penyakit Gigi dan Mulut Manusia Menggunakan Knowledge Base System dan Certainty Factor. Jurnal Ilmiah Teknologi dan Informatika ASIA (JITIKA) Vol.10, No.2.

[8] Sakul, K. A. (2017). Perancangan Sistem Pelaporan Tanam Dan Hasil Pertanian Di Wilayah Kabupaten Bandung Barat Berbasis Android.

[9] Iskandar, \& Sitanggang, M. (2003). Memilih \& Merawat Maskoki Impor Berkualitas. Jakarta: PT AgroMedia Pustaka.

[10] Ardhya, R. E. (2013). Analisis Faktor-faktor Yang Mempengaruhi Produksi Dan Pendapatan Usaha Budidaya Ikan Mas Koki. 